\title{
PPARD $+294 C$ overrepresentation in general and long-lived population in China Bama longevity area and unique relationships between PPARD +294T/C polymorphism and serum lipid profiles
}

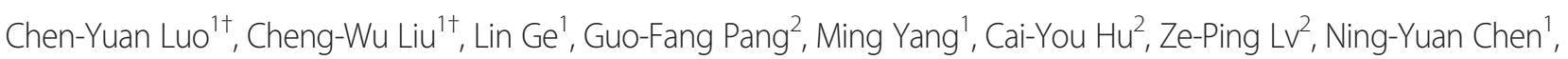
Hai-Yan Li ${ }^{1}$, Hua-Yu Wu ${ }^{3}$, Yi-Yuan Wang ${ }^{1}$, Rui-Xing Yin ${ }^{4}$, Shang-Ling Pan ${ }^{1}$ and Jun-Hua Peng ${ }^{1 *}$

\begin{abstract}
Background: The $+294 \mathrm{~T} / \mathrm{C}$ polymorphism in the peroxisome proliferator-activated receptor delta (PPARD) gene is associated with hyperlipidemia in several younger populations, but results are still inconsistence across ethnic groups and its possible impact on the lipid profiles of long-lived individuals remains unexploited. Here, we aimed to evaluate the possible correlation between PPARD +294 T/C and serum lipid levels in a long-lived population in Bama, a region known for longevity situated in Guangxi, China.

Methods: Genotyping of PPARD +294 T/C polymorphism was conducted in 505 long-lived inhabitants (aged 90 and above, long-lived group, LG) and 468 healthy controls (aged 60-75, non-long-lived group, non-LG) recruited from Bama area.
\end{abstract}

Results: No difference in allelic and genotypic frequencies was found between the two groups $(P>0.05)$. However, C-allele and C-genotype (TC and CC) were significantly more frequent in the females of non-LG than were LG after sex stratification. CC carriers exhibited higher LDL-C level in LG $(P<0.05)$ but lower TC, TG and LDL-C in non-LG $(P<0.05$ for each) than $T$ carriers; $C$ allele carriers (TC/CC) in LG exhibited higher TC, TG, and LDL-C levels as compared with the same genotype and the same lipid parameter in non-LG ( $P<0.05$ for each). LDL-C in LG was correlated with genotypes while TC, TG, and LDL-C in non-LG were correlated with genotypes $(P<0.05-0.001)$.

Conclusion: Our results suggest that there were different impact patterns of PPARD +294 T/C polymorphism on lipid profiles between long-lived cohort and average population in Bama area and this may be one of the genetic bases of its longevity.

Keywords: Peroxisome proliferator-activated receptor delta (PPARD), Longevity, Lipoprotein, Polymorphism, Association study

\footnotetext{
* Correspondence: pengjh@gxmu.edu.cn

${ }^{\dagger}$ Equal contributors

'Department of Pathophysiology, School of Preclinical Medicine, Guangxi Medical University, 22 Shuangyong Road, Nanning, Guangxi 530021, People's Republic of China

Full list of author information is available at the end of the article
} 


\section{Introduction}

The peroxisome proliferator-activated receptors (PPARs) belong to a superfamily of nuclear receptors. Three subtypes of PPARs, $\alpha, \gamma$ and $\delta$, have been identified to date, with distinct roles in lipid and glucose metabolism. They are encoded by separate genes and characterized by distinct tissue-specific distribution patterns. PPAR $\alpha$ and $\gamma$ are primarily produced in the liver and adipocytes respectively and regulate fatty acid oxidation and adipogenesis accordingly, whereas PPAR $\delta$ is ubiquitously expressed, with higher levels found in adipose tissue and skeletal muscle which might involve in the regulation of the $\beta$-oxidation of fatty acid [1-4]. In this context, disturbance in levels or activity of PPARs may elicit metabolic traits. In recent years, a number of efforts have thus been directed to the putative link between PPARs and age-related phenotypes such as metabolic syndrome, coronary heart disease (CHD) and Alzheimer's disease (AD) $[5,6]$, some of which have been well established both in animal and human models. Of these, PPAR $\delta$ has been of burgeoning interest and proposed as a key player in the regulation of energy metabolism due to its ability to enhance fatty acid catabolism, energy uncoupling and insulin sensitivity in multiple tissues [7].

The PPARD gene that encodes human PPAR $\delta$ is mapped to 6p21.2-p21.1 with 11 exons encompassing $35 \mathrm{Kbp}$ [8]. Recent works have highlighted the potential roles for functional variants in PPARD gene in modulating its mRNA and protein levels which, in turn, affect genes regulated by PPARD [9-14]. Nine most common polymorphisms had been identified in PPARD: four in the intron, one in the $5^{\prime}$ untranslated region, and four in the 3' untranslated region: c. $-13598 \mathrm{C}>\mathrm{T}$, c. $-13454 \mathrm{G}>$ T, c. $+294 \mathrm{~T}>\mathrm{C}$, c. $285+700 \mathrm{~T}>\mathrm{C}$, c. $285+793 \mathrm{C}>\mathrm{T}$, c. $2022+12 \mathrm{G}>$ A, c. $2022+351 \mathrm{~T}>\mathrm{C}$, c. $2629 \mathrm{~T}>\mathrm{C}$, and c. 2806C > G [9]. One of them, +294 $\mathrm{T}>\mathrm{C}(\mathrm{rs} 2016520$, also named $-87 \mathrm{~T}>\mathrm{C}$ or $+15 \mathrm{C}>\mathrm{T}$ ), a $\mathrm{T} / \mathrm{C}$ transition in nucleotide 15 of exon 4 located 87 base pairs before the start codon, is mostly studied in view of its critical role in lipid modulation $[7,12]$. The rare $C$ allele versus the common $\mathrm{T}$ allele was shown to be associated with higher transcriptional activity and to influence binding of Sp-1 transcription factor [15]. Furthermore, subjects homogenous for $\mathrm{C}$ allele showed higher low density lipoprotein (LDL-C) level and a propensity towards a higher risk of CHD than T/T homozygotes [12,13,15-18], albeit conflicting results still exist in diverse populations [17-19]. Very recently, PPAR $\delta$ was indicated to have anti-senescence activity in cultured human coronary artery endothelial cells [14]. Together, these results address that PPARD $+294 \mathrm{~T} / \mathrm{C}$ polymorphism may play pivotal roles in the development of metabolic perturbations and subsequent aged-related pathologies, impacting consequently mortality and longevity in a given population. However, it is worth noting that the association studies between PPARD $+294 \mathrm{~T} / \mathrm{C}$ polymorphism and serum lipid profiles were primarily undertaken in younger cohorts of European ancestry, data from population with exceptional longevity, particularly from China's minorities, are evidently scarce. Bama long-lived individuals, a unique cohort reside along the midstream of Hongshuihe River in Guangxi Province, P. R. China, has emerged as an optimal cohort for human aging/ longevity study in view of its low genetic background over the past decades [20]. Herein, we set out to test the hypothesis that the PPARD $+294 \mathrm{~T} / \mathrm{C}$ polymorphism is associated with plasma lipid profile and longevity in Bama nonagenarians/centenarians of Zhuang ethnic origin.

\section{Materials and methods \\ Study population}

We studied 505 nonagenarians/centenarians (127 males and 378 females, age $93.29 \pm 2.93$ and range $90-104$ years, referred to hereafter as the long-lived group or LG) who were recruited from Bama area (Bama, Fengshan, Donglan, and Du'an County) along the midstream of Hongshuihe River Basin, Guangxi Zhuang Autonomous Region, the People's Republic of China. A total of 468 volunteers (212 males and 256 females, age $68.28 \pm 4.66$ and range 60-75 years) without a familial history of exceptional longevity (no past or current nonagenarian/ centenarian in the first, second and third degree relatives) were randomly recruited as controls (non-longlived group, non-LG) from the same geographic region. All subjects under investigation were unrelated and belong to Zhuang ethnic group, the China's largest minority mainly living in Guangxi. All subjects were essentially healthy and had no evidence of any chronic illness, including hepatic, renal, or thyroid. The participants with a history of myocardial infarction, stroke, diabetes were also excluded. The current study was approved by the Ethics Committee of Guangxi Medical University. Informed consent was obtained from all subjects or their proxies after receiving full explanation of the study.

\section{Epidemiological survey}

Socio-demographic information was obtained using a standardized questionnaire. Anthropometric variables including height, weight and waist were measured in all groups. Body mass index (BMI) was calculated as weight $(\mathrm{kg}) /$ height $^{2}(\mathrm{~m})$. Sitting blood pressure was measured 3 times, using a standard mercury sphygmomanometer with the subject resting for at least 5 minutes before measurement, and the average of the 3 measurements was used for the level of blood pressure. Systolic blood pressure was determined by the first Korotkoff sound; and diastolic, by the fifth Korotkoff sound. Hypertension 
was defined as systolic blood pressure $>140 \mathrm{mmHg}$ and/ or diastolic blood pressure $>90 \mathrm{mmHg}$. Normal weight, overweight, and obesity were defined as a $\mathrm{BMI}<24,24$ to 28 , and $>28 \mathrm{~kg} / \mathrm{m}^{2}$, respectively [21].

\section{Biochemical measurements}

A venous blood sample of $8 \mathrm{~mL}$ was drawn from each subject after an overnight fast, $4 \mathrm{~mL}$ of which was for serum separation and subsequent lipid determination while the remaining was transferred to an anticoagulant tube $(4.80 \mathrm{~g} / \mathrm{L}$ citric acid, $14.70 \mathrm{~g} / \mathrm{L}$ glucose, and $13.20 \mathrm{~g} / \mathrm{L}$ trisodium citrate) for DNA extraction. Total cholesterol (TC), triglycerides (TG), LDL-C and high density lipoprotein cholesterol (HDL-C) concentrations were measured by standard enzymatic methods using commercially available kits (Daiichi Pure Chemicals Co, Ltd., Tokyo, Japan) on a biochemical analyzer (Type 7170A; Hitachi Ltd, Tokyo, Japan) at the Clinical Science Experimental Center of the First Affiliated Hospital, Guangxi Medical University. The normal ranges of serum TC, TG, HDL-C, and LDL-C levels in the Center were 3.10-5.17, 0.56-1.70, 0.91-1.81, and 1.70$3.20 \mathrm{mmol} / \mathrm{L}$, respectively. The individuals with $\mathrm{TC}>$ $5.17 \mathrm{mmol} / \mathrm{L}$ and/or TG $>1.70 \mathrm{mmol} / \mathrm{L}$ were defined as hyperlipidemic or dyslipidemia [22].

\section{Genotyping}

Genomic DNA was extracted from white blood cells using standard methods [23]. Genotyping for the PPARD +294 $\mathrm{T}>\mathrm{C}$ polymorphism was performed using polymerase chain reaction (PCR)-based restriction fragment length polymorphism (RFLP) as described by Wang et al. [24]. Briefly, a 269 bp fragment in the 5 '-untranslated region of exon 4 of the PPARD gene was amplified by using primers 5'-CATGGTATAGCACTGCAG GAA-3' (forward) and 5'-CTTCCTCCTGTGGCTGC TC-3' (reverse) (Sangon Biotech, China). PCR was performed in a volume of $20 \mu \mathrm{L}$ containing $200 \mathrm{ng}$ of genomic DNA, $10 \mu \mathrm{L}$ of Taq MasterMix (Beijing CoWin Bioscience, China), $6.25 \mu \mathrm{M}(1.0 \mu \mathrm{L})$ of each primer,

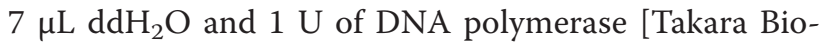
technology, DaLian, China]. PCR conditions were: $95^{\circ} \mathrm{C}$ for an initial $5 \mathrm{~min}$, followed by 35 cycles of $95^{\circ} \mathrm{C}$ $45 \mathrm{sec}, 62^{\circ} \mathrm{C} 45 \mathrm{sec}$, and $72^{\circ} \mathrm{C} 45 \mathrm{sec}$, with a final $5 \mathrm{~min}$ extension at $72^{\circ} \mathrm{C}$. The PCR products $(10 \mu \mathrm{L})$ were digested with Bsl I (5 U) restriction endonuclease (New England Biolabs, Beijing, China) at $55^{\circ} \mathrm{C}$ overnight, and the fragments were separated on a $3 \%$ agarose gel containing ethidium-bromide and visualized with UV light. Band(s) at 269 bp only, at 269, 167, and $102 \mathrm{bp}$, and at 167, $102 \mathrm{bp}$ indicate(s) TT, TC, and $\mathrm{CC}$ genotype, respectively (Figure 1A). To assess genotyping reliability, six samples (two for each genotype) were confirmed by direct sequencing in Sangon Biological Engineering Technology \& Services Co., Ltd., China (Figure 1B). Laboratory technicians who performed genotyping were masked to clinical and biochemical data.

\section{Statistical analysis}

Levels of the quantitative variables are presented as mean \pm SD. Allelic and genotypic frequencies were



Figure 1 Genotype results of PPARD +294T/C polymorphism. (A) Lane M, 100 bp marker ladder; lanes 1, PCR product; lane 2, 3, TT genotype (269 bp); lane 4, 5, CC genotype (167- and 102-bp); and lanes 6, 7, TC genotype (269-, 167- and 102-bp). (B) Partial nucleotide sequences of PPARD +294 T/C SNP. CC, T, and TC genotypes. 
calculated directly. Comparison of mean values of general characteristics between study groups and test for Hardy-Weinberg equilibrium were performed with the Pearson chi-square test. The statistical evaluation for the categorical variables was based on the calculation of the Student t-test. The association between the $+294 \mathrm{~T} / \mathrm{C}$ polymorphism and lipid variables was tested by analysis of covariance (ANCOVA). Multiple logistic analyses with stepwise modeling were used to evaluate the association of serum lipid levels with genotypes ( $\mathrm{TT}=1, \mathrm{TC}=2, \mathrm{CC}=3$ ) and several environment factors. All reported $P$ values are from two-sided tests. A P-value $<0.05$ was considered statistically significant. All analyses were performed using SPSS 13.0 (SPSS Inc, Chicago, IL).

\section{Results}

\section{General characteristics and serum lipid levels}

The basic demographic, clinical, and biochemical characteristics of participants of LG and non-LG are shown in Table 1. BMI was significantly lower in the LG as compared to non-LG group $(P=0.001)$. The levels of blood pressure, hypertension rate and unfavorable lipoprotein (TC, TG and LDL-C) were significantly higher $(P<0.01$ for all $)$ while the level of favorable lipoprotein (HDL-C) was slightly lower but did not reach statistical significance in LG than in controls. Despite the higher lipoprotein levels in LG, however,

Table 1 Comparison of clinical characteristics and serum lipid profiles between LG and non-LG

\begin{tabular}{lllll}
\hline Parameter & LG $(\mathbf{n}=\mathbf{5 0 5})$ & Non-LG $(\mathbf{n}=\mathbf{4 6 8})$ & $\boldsymbol{t}\left(\boldsymbol{x}^{\mathbf{2}}\right)$ & $\boldsymbol{P}$ \\
\hline N (male/female) & $127 / 378$ & $212 / 256$ & 43.445 & 0.000 \\
Age (years) & $93.29 \pm 2.93$ & $68.28 \pm 4.66$ & 41.967 & 0.000 \\
Chest $(\mathrm{cm})$ & $79.38 \pm 7.28$ & $81.30 \pm 7.21$ & -4.057 & 0.000 \\
Waist (cm) & $77.02 \pm 9.52$ & $75.73 \pm 9.26$ & 2.101 & 0.036 \\
Hip (cm) & $84.25 \pm 6.62$ & $87.06 \pm 6.38$ & -6.588 & 0.927 \\
BMI (kg/m $\left.{ }^{2}\right)$ & $20.22 \pm 3.43$ & $20.94 \pm 3.17$ & -3.401 & 0.001 \\
SBP (mmHg) & $166.23 \pm 28.14$ & $149.45 \pm 25.31$ & 9.792 & 0.000 \\
DBP (mmHg) & $89.21 \pm 13.65$ & $84.76 \pm 12.28$ & 5.342 & 0.000 \\
TC (mM) & $5.08 \pm 1.01$ & $4.91 \pm 0.94$ & 2.656 & 0.008 \\
TG (mM) & $0.97(0.49)$ & $0.93(0.47)$ & 1.878 & 0.006 \\
HDL-C (mM) & $1.58 \pm 0.38$ & $1.62 \pm 0.37$ & -1.550 & 0.122 \\
LDL-C (mM) & $3.00 \pm 0.86$ & $2.82 \pm 0.80$ & 3.491 & 0.001 \\
Dyslipidemia n(\%) & $240(47.52)$ & $204(43.59)$ & 1.516 & 0.218 \\
Hypertension n(\%) & $425(84.16)$ & $290(61.97)$ & 61.396 & 0.000 \\
\hline
\end{tabular}

LG, long-lived group; non-LG, non-long-lived group; BMI: body mass index; SBP, systolic blood pressure; DBP, diastolic blood pressure; TC, total cholesterol; TG, triglyceride; HDL-C, high-density lipoprotein cholesterol; LDL-C, low-density lipoprotein cholesterol. The values of triglyceride were presented as median (interquartile range) due to non-Gaussian distribution. The difference between the two groups was determined by the Wilcoxon-Mann-Whitney test. the prevalence of dyslipidemia was similar between LG and non-LG $(P=0.218)$.

\section{PPARD +294T/C polymorphism}

The frequencies of the minor $\mathrm{C}$-allele were $29.3 \%$ and $32.9 \%$ in LG and non-LG, respectively, and the genotypes were distributed according to the Hardy Weinberg Equilibrium in both groups. Overall, no significant difference was observed in the frequency distribution of genotypes and alleles between the two groups (both $P>0.05)$. When gender was taken into account, this distribution pattern remained similar in both sexes in intragroup comparison, but appeared to lose in females in intergroup comparison, with $\mathrm{C}$-allele and $\mathrm{TC} / \mathrm{CC}$ genotype tending to present more frequently in nonLG females than that in LG albeit the statistic powers were less robust (Table 2).

\section{Genotypes and serum lipid levels}

In long-lived individuals, while levels of TC, TG, and HDL-C appeared similar across genotypes, there was a trend toward higher LDL-C in CC carriers relative to $\mathrm{T}$ carriers (TT/TC), but this tendency was no longer existed when analyses were stratified by sex. By contrary, in non-long-lived controls however, LDL-C tended to be lower in $\mathrm{C}$ allele carriers (TC/CC) than did TT carriers. Similar propensities were also observed on TC and TG levels in this group, even after sex was analyzed separately, especially in men. Intergroup comparison showed that TC, TG, and LDL-C levels of $C$ allele carriers (TC and CC) but not TT carriers in LG, regardless of sex, were significantly higher than that of non-LG, implying that the minor $\mathrm{C}$ but not the wild type $\mathrm{T}$ allele may account in part for the difference of lipid profiles between LG and non-LG (Table 3).

\section{Correlation between serum lipid parameters and genotypes}

Multiple linear regression analyses showed that in the combined population, the four lipid parameters were mainly correlated positively with factors such as age, sex (female), BMI and diastolic blood pressure. When studied group was considered separately, LDL-C in LG was also noted to correlate positively with genotypes while TC, TG, and LDL-C in non-LG negatively with genotypes besides the above factors (Table 4). These findings are basically in line with results in Table 1 and Table 3.

\section{Discussion}

In the present study, the long-lived individuals exhibited significant higher TC, TG, and LDL-C levels than their younger counterparts. Higher mean age of the LG could not fully explain these differences. Our major 
Table 2 Comparison of genotypic and allelic frequency of the PPARD +294T/C polymorphism between LG and non-LG

\begin{tabular}{|c|c|c|c|c|c|c|}
\hline \multirow[t]{2}{*}{ Subgroup } & \multirow[t]{2}{*}{$n$} & \multicolumn{3}{|c|}{ Genotype $\mathbf{n}(\%)$} & \multicolumn{2}{|c|}{ Allele $\mathrm{n}(\%)$} \\
\hline & & $\overline{\mathrm{TT}}$ & TC & CC & $\overline{\mathrm{T}}$ & C \\
\hline$\overline{L G}$, all & 505 & $261(51.70)$ & 192(38.00) & $52(10.30)$ & $714(70.70)$ & $296(29.30)$ \\
\hline Non-LG, all & 468 & $212(45.30)$ & $204(43.60)$ & $52(11.10)$ & 628(67.09) & 308(32.91) \\
\hline$x^{2}$ & & & & 4.039 & & 2.94 \\
\hline P & & & & 0.133 & & 0.086 \\
\hline LG, male & 127 & $58(45.70)$ & $56(44.10)$ & 13(10.20) & $172(67.70)$ & $82(32.30)$ \\
\hline LG, female & 378 & 203(53.70) & $136(36.00)$ & $39(10.30)$ & $542(71.70)$ & $214(28.30)$ \\
\hline$x^{2}$ & & & & 2.835 & & 1.451 \\
\hline P & & & & 0.242 & & 0.228 \\
\hline Non-LG, male & 212 & $100(47.20)$ & $88(41.50)$ & $24(11.30)$ & $288(67.90)$ & $136(32.10)$ \\
\hline Non-LG, female & 256 & $112(43.80)$ & 116(45.30) & $28(10.90)$ & $340(66.40)$ & 172(33.60) \\
\hline$x^{2}$ & & & & 0.700 & & 0.242 \\
\hline P & & & & 0.705 & & 0.623 \\
\hline LG, male & 127 & $58(45.70)$ & $56(44.10)$ & 13(10.20) & 172(67.70) & $82(32.30)$ \\
\hline Non-LG, male & 212 & $100(47.20)$ & $88(41.50)$ & $24(11.30)$ & $288(67.90)$ & 136(32.10) \\
\hline$x^{2}$ & & & & 0.249 & & 0.003 \\
\hline P & & & & 0.883 & & 0.955 \\
\hline LG, female & 378 & 203(53.70) & $136(36.00)$ & $39(10.30)$ & $542(71.70)$ & $214(28.30)$ \\
\hline Non-LG, female & 256 & $112(43.80)$ & 116(45.30) & $28(10.90)$ & $340(66.40)$ & $172(33.60)$ \\
\hline$x^{2}$ & & & & 6.444 & & 4.030 \\
\hline P & & & & 0.040 & & 0.045 \\
\hline
\end{tabular}

concern is whether, and if so, to what extent the polymorphism of PPARD +294 involves in the modulation of lipid profile and longevity trait in these cohorts.

One of the important findings herein is the relatively higher frequency of the minor $\mathrm{C}$ allele of the PPARD +294 polymorphism, being $31.04 \%$ for the entire participants investigated, similar to that of healthy middle-aged Bai $\mathrm{Ku}$ Yao (22.50\%) and Guangxi Han Chinese (27.57\%) [17], two isolated subpopulations living in the branches of the upstream of Hongshuihe River, but noticeably higher than that of healthy Anhui Han Chinese (19.5\%) [24], Korean (22.9\%) [9], Swedish (15.6\%) [15], Tunisian (18.9\%) [18], Russian (12.1\%) [25], German (19.2\%) [19], and FrenchCanadians (20.1\%) [11], demonstrating a populationspecific allelic distribution pattern worldwide. The driving forces and the significance of this polymorphism in our studying population deserve further investigation.

The second finding in the current study is the marginal overrepresentation of minor $\mathrm{C}$ allele and genotypes $(\mathrm{TC} / \mathrm{CC})$ in the females of non-LG relative to that of LG $(P=0.040,0.045$, respectively, Table 2.) and the inverse relationship between PPARD $+294 \mathrm{C}$ ratio and lipid levels in the serum in non-long-lived group.
Hitherto, the associations between PPARD $+294 \mathrm{C}$ and dyslipidemia, CHD, and other age-related pathologies have been replicated in several populations. For instance, elevated level of LDL-C was found in CC enotype carriers as compared to wild type TT homozygotes in Swedish healthy men [15], disease-free middle-aged Guangxi Han Chinese [17], and German mild obese and dyslipidemia patients [5]; the C-allele was significantly more frequent in Tunisian patients with cardiovascular artery disease than in controls [18]. Nevertheless, of interest to note is that subjects homozygous and heterozygous for PPARD $+294 \mathrm{C}$ variant in non-LG had lower, instead of higher, levels of TC, TG and LDL-C. We have no exact explanation on these controversial results because, according to published literatures, the transition of nucleotide $\mathrm{T}$ to $C$ at PPARD +294 may relate to either raised or no-change but not decreased level of unfavorable lipid.

In line with the preponderant view on the disadvantageous role that PPARD $+294 \mathrm{C}$ may play in lipid modulation, we found a positive correlation between this polymorphism and lipid levels in long-lived group, which accounted for the third finding in our study. Thus, it seems reasonable that the females in LG present less C allele and CC genotype and this might confer them more 
Table 3 Impact of PPARD +294T/C genotype on lipid levels

\begin{tabular}{|c|c|c|c|c|c|c|}
\hline Subgroup & Genotype & $n$ & $\mathrm{TC}(\mathrm{mmol} / \mathrm{L})$ & TG (mmol/L) & $\mathrm{HDL}-\mathrm{C}(\mathrm{mmol} / \mathrm{L})$ & LDL-C (mmol/L) \\
\hline \multirow[t]{4}{*}{$\overline{L G}$, all } & $\pi$ & 261 & $5.05 \pm 0.99$ & $0.96(0.49)$ & $1.58 \pm 0.39$ & $2.97 \pm 0.83$ \\
\hline & $\mathrm{TC}$ & 192 & $5.03 \pm 1.01^{b}$ & $0.97(0.49)^{b}$ & $1.60 \pm 0.36$ & $2.97 \pm 0.90^{\mathrm{b}}$ \\
\hline & CC & 52 & $5.40 \pm 1.06^{\mathrm{b}}$ & $1.10(0.48)^{b}$ & $1.54 \pm 0.35$ & $3.31 \pm 0.83^{\mathrm{ab}}$ \\
\hline & $\mathrm{TC} / \mathrm{CC}$ & 244 & $5.11 \pm 1.03^{b}$ & $0.98(0.50)^{b}$ & $1.58 \pm 0.36^{b}$ & $3.04 \pm 0.89^{b}$ \\
\hline \multirow[t]{4}{*}{ LG, male } & $\pi$ & 58 & $4.76 \pm 1.04^{c}$ & $0.97(0.48)$ & $1.52 \pm 0.41$ & $2.75 \pm 0.95^{c}$ \\
\hline & $\mathrm{TC}$ & 56 & $4.73 \pm 1.07^{c}$ & $0.89(0.36)^{c}$ & $1.53 \pm 0.40$ & $2.77 \pm 0.92$ \\
\hline & $C C$ & 13 & $5.37 \pm 1.00^{d}$ & $0.94(0.26)$ & $1.64 \pm 0.53$ & $3.30 \pm 0.61^{d}$ \\
\hline & $\mathrm{TC} / \mathrm{CC}$ & 69 & $4.85 \pm 1.08^{c}$ & $0.92(0.33)^{c}$ & $1.55 \pm 0.43$ & $2.87 \pm 0.89$ \\
\hline \multirow[t]{4}{*}{ LG, female } & $\pi$ & 203 & $5.13 \pm 0.96$ & $0.96(0.50)$ & $1.60 \pm 0.39$ & $3.03 \pm 0.78$ \\
\hline & $\mathrm{TC}$ & 136 & $5.15 \pm 0.97^{d}$ & $1.02(0.64)^{d}$ & $1.62 \pm 0.35$ & $3.05 \pm 0.88^{d}$ \\
\hline & CC & 39 & $5.41 \pm 1.09$ & $1.15(0.56)$ & $1.51 \pm 0.27^{d}$ & $3.32 \pm 0.90$ \\
\hline & $\mathrm{TC} / \mathrm{CC}$ & 175 & $5.21 \pm 1.00^{d}$ & $1.04(0.63)^{d}$ & $1.59 \pm 0.33^{d}$ & $3.11 \pm 0.89^{d}$ \\
\hline \multirow[t]{4}{*}{ Non-LG, all } & $\pi$ & 212 & $5.04 \pm 0.91$ & $0.97(0.55)$ & $1.61 \pm 0.38$ & $2.93 \pm 0.80$ \\
\hline & $\mathrm{TC}$ & 204 & $4.77 \pm 0.93$ & $0.91(0.43)$ & $1.63 \pm 0.38$ & $2.71 \pm 0.79$ \\
\hline & CC & 52 & $4.92 \pm 0.99^{a}$ & $0.88(0.53)^{a}$ & $1.64 \pm 0.32$ & $2.79 \pm 0.82^{\mathrm{a}}$ \\
\hline & $\mathrm{TC} / \mathrm{CC}$ & 256 & $4.80 \pm 0.95^{\mathrm{a}}$ & $0.89(0.44)^{\mathrm{a}}$ & $1.63 \pm 0.37$ & $2.72 \pm 0.79^{a}$ \\
\hline \multirow[t]{4}{*}{ Non-LG, male } & $\pi$ & 100 & $4.96 \pm 0.95$ & 0.95(0.75) & $1.57 \pm 0.37$ & $2.87 \pm 0.85$ \\
\hline & $\mathrm{TC}$ & 88 & $4.65 \pm 1.05$ & $0.91(0.49)$ & $1.58 \pm 0.37$ & $2.63 \pm 0.87$ \\
\hline & $C C$ & 24 & $4.59 \pm 0.80^{c}$ & $0.88(0.37)^{a}$ & $1.52 \pm 0.24^{c}$ & $2.66 \pm 0.72$ \\
\hline & $\mathrm{TC} / \mathrm{CC}$ & 112 & $4.64 \pm 1.00^{\mathrm{ac}}$ & $0.90(0.48)^{\mathrm{a}}$ & $1.57 \pm 0.35^{c}$ & $2.63 \pm 0.84^{\mathrm{a}}$ \\
\hline \multirow[t]{4}{*}{ Non-LG, female } & $\Pi$ & 112 & $5.11 \pm 0.88$ & $1.00(0.41)$ & $1.65 \pm 0.38$ & $2.99 \pm 0.76$ \\
\hline & $\mathrm{TC}$ & 116 & $4.86 \pm 0.82$ & $0.91(0.35)$ & $1.66 \pm 0.39$ & $2.77 \pm 0.72$ \\
\hline & CC & 28 & $5.21 \pm 1.07$ & $0.87(0.61)$ & $1.74 \pm 0.35$ & $2.90 \pm 0.90$ \\
\hline & $\mathrm{TC} / \mathrm{CC}$ & 144 & $4.93 \pm 0.88$ & $0.89(0.43)^{a}$ & $1.68 \pm 0.38$ & $2.80 \pm 0.75^{a}$ \\
\hline
\end{tabular}

${ }^{\mathrm{a}} P<0.05$ in comparison with $\Pi$ genotype of the same group; ${ }^{\mathrm{b}} P<0.05$ in comparison with the same genotype between LG and non-LG; ${ }^{\mathrm{c}} P<0.05$ intra-group comparison with the same genotype between sexes; ${ }^{d} P<0.05$ intergroup comparison with the same genotype in males or females.

opportunity to achieve longer lifespan than non-LG. However, we could not answer the question why the males in LG who presented similar C allele as general controls outlived their nineties.

Admittedly, lipid profiles and longevity are much more complex phenotypes which can not be interpreted with sole gene polymorphism. We speculate that the influence of PPARD + T294C on lipid metabolism, if any, may be limited, as do other lipid modulating genes such as cholesteryl ester transfer protein (CETP) [26] and microsomal triglyceride transfer protein (MTP) gene [20], each of which exerting small but pleiotropic effect on these complex traits, and this influence may concomitantly be affected by diet, lifestyle, and the interaction with other lipid related genes and environment via unraveled pathways.

To sum, our data show that inhabitants residing in Bama region of Guangxi, China display a higher minor allele frequency of the PPARD $+294 \mathrm{~T} / \mathrm{C}$ polymorphism than other populations, with more $\mathrm{C}$ allele and C-containing genotypes representing in younger controls relative to long-lived individuals. Homozygous CC genotype is associated with increased LDL-C level in long-lived cohort whereas with decreased TC, TG and LDL-C levels in non-long-lived counterparts, demonstrating its age range-specific pattern on lipid profiles. The lower levels of unfavorable lipids in the average population in Bama area may relate to lower morbidity and mortality of age-associated diseases and this may in part pave the way to the longevity of the region. To the best of our knowledge, unlike others who mainly focused on younger healthy or patient populations, our research group is the first team to explore this polymorphism in long-lived and general individuals from a unique longevous region and report a reduced unfavorable lipids associated with PPARD +294C. However, longitudinal follow-up studies and gene functional studies are needed to further elucidate the precise effects of PPARD $+294 \mathrm{~T} / \mathrm{C}$ polymorphism on serum lipids and longevity in Bama area. 
Table 4 Correlation between serum lipid parameters and PPARD +294T/C genotypes

\begin{tabular}{|c|c|c|c|c|c|c|}
\hline Lipid & $\begin{array}{l}\text { Relative } \\
\text { factor }\end{array}$ & $\begin{array}{l}\text { Unstandardized } \\
\text { coefficient }\end{array}$ & $\begin{array}{l}\text { Standard } \\
\text { error }\end{array}$ & $\begin{array}{l}\text { Standardized } \\
\text { coefficient }\end{array}$ & $t$ & $P$ \\
\hline \multicolumn{7}{|c|}{ LG plus non-LG } \\
\hline \multirow[t]{2}{*}{ TC } & $\mathrm{DBP}$ & 0.012 & 0.002 & 0.158 & 4.905 & 0.000 \\
\hline & Gender & 0.306 & 0.065 & 0.150 & 4.679 & 0.000 \\
\hline \multirow[t]{3}{*}{ TG } & $\mathrm{BMl}$ & 0.009 & 0.002 & 0.176 & 5.337 & 0.000 \\
\hline & DBP & 0.001 & 0.000 & 0.091 & 2.769 & 0.006 \\
\hline & Age & 0.001 & 0.000 & 0.075 & 2.266 & 0.024 \\
\hline \multirow[t]{3}{*}{ HDL-C } & $\mathrm{BMI}$ & -0.012 & 0.004 & -0.111 & -3.375 & 0.001 \\
\hline & Gender & 0.085 & 0.026 & 0.108 & 3.248 & 0.001 \\
\hline & Age & -0.003 & 0.001 & -0.090 & -2.688 & 0.007 \\
\hline \multirow[t]{4}{*}{ LDL-C } & $\mathrm{DBP}$ & 0.007 & 0.002 & 0.115 & 3.468 & 0.001 \\
\hline & Gender & 0.264 & 0.065 & 0.151 & 4.046 & 0.000 \\
\hline & Age & 0.009 & 0.003 & 0.129 & 3.388 & 0.001 \\
\hline & Weight & 0.010 & 0.004 & 0.114 & 2.661 & 0.008 \\
\hline \multicolumn{7}{|l|}{ LG } \\
\hline \multirow[t]{2}{*}{ TC } & $\mathrm{DBP}$ & 0.013 & 0.003 & 0.175 & 3.900 & 0.000 \\
\hline & Gender & 0.344 & 0.104 & 0.149 & 3.318 & 0.001 \\
\hline \multirow[t]{2}{*}{$\mathrm{TG}$} & Weight & 0.005 & 0.001 & 0.239 & 4.653 & 0.000 \\
\hline & Gender & 0.078 & 0.019 & 0.213 & 4.150 & 0.000 \\
\hline \multirow[t]{2}{*}{$\mathrm{HDL}-\mathrm{C}$} & Weight & -0.007 & 0.002 & -0.147 & -3.204 & 0.001 \\
\hline & DBP & 0.002 & 0.001 & 0.091 & 1.981 & 0.048 \\
\hline \multirow[t]{4}{*}{ LDL-C } & $\mathrm{DBP}$ & 0.008 & 0.003 & 0.130 & 2.878 & 0.004 \\
\hline & Gender & 0.386 & 0.105 & 0.196 & 3.660 & 0.000 \\
\hline & Genotype & 0.136 & 0.057 & 0.107 & 2.384 & 0.018 \\
\hline & Height & 0.009 & 0.004 & 0.119 & 2.236 & 0.026 \\
\hline \multicolumn{7}{|l|}{ non-LG } \\
\hline \multirow[t]{4}{*}{ TC } & Height & -0.016 & 0.005 & -0.154 & -3.244 & 0.001 \\
\hline & Waist & 0.012 & 0.005 & 0.115 & 2.453 & 0.015 \\
\hline & Genotype & -0.148 & 0.064 & -0.107 & -2.309 & 0.021 \\
\hline & $\mathrm{DBP}$ & 0.008 & 0.004 & 0.102 & 2.181 & 0.030 \\
\hline \multirow[t]{4}{*}{$\mathrm{TG}$} & BMI & 0.022 & 0.004 & 0.383 & 5.601 & 0.000 \\
\hline & Hip & -0.006 & 0.002 & -0.209 & -3.057 & 0.002 \\
\hline & Genotype & -0.034 & 0.012 & -0.130 & -2.915 & 0.004 \\
\hline & DBP & 0.002 & 0.001 & 0.111 & 2.444 & 0.015 \\
\hline \multirow[t]{3}{*}{ HDL-C } & Waist & -0.007 & 0.002 & -0.168 & -3.685 & 0.000 \\
\hline & Gender & 0.108 & 0.035 & 0.143 & 3.118 & 0.002 \\
\hline & Age & -0.005 & 0.002 & -0.121 & -2.627 & 0.009 \\
\hline \multirow[t]{4}{*}{ LDL-C } & Waist & 0.019 & 0.005 & 0.224 & 3.651 & 0.000 \\
\hline & SBP & 0.004 & 0.001 & 0.122 & 2.657 & 0.008 \\
\hline & Genotype & -0.131 & 0.055 & -0.109 & -2.371 & 0.018 \\
\hline & Weight & -0.011 & 0.005 & -0.127 & -2.070 & 0.039 \\
\hline
\end{tabular}

DBP: Diastolic blood pressure; SBP: Systolic blood pressure; BMI: Body mass index. 


\section{Competing interests}

The authors declare that they have no competing interests.

\section{Authors' contributions}

CYL participated in the design of the study, undertook the genotyping, performed the statistical analyses, and drafted the manuscript. JHP conceived the study, participated in the design, organized the epidemiological survey and sampling, and helped to draft the manuscript. CWL supervised the genotyping, data analyses and the manuscript writing. LG, PGF, MY, CYH, ZPL, NYC, HYL, HYW, YYW, RXY, and SLP participated in the field study. All authors read and approved the final manuscript.

\section{Acknowledgments}

We especially thank all of those who donated samples. This study was supported by the National Natural Science Foundation of China (No. 30860126, 31160209) and the Natural Science Foundation of Guangxi (No. 2010GXNSFA013153, 2013GXNSFAA019180, 2013GXNSFBB053002).

\section{Author details}

${ }^{1}$ Department of Pathophysiology, School of Preclinical Medicine, Guangxi Medical University, 22 Shuangyong Road, Nanning, Guangxi 530021, People's Republic of China. 'Department of Neurology, Jiangbin Hospital of Guangxi Zhuang Autonomous Region, 85 Hedi Road, Nanning, Guangxi 530021, People's Republic of China. ${ }^{3}$ Department of Cell Biology \& Genetics, School of Preclinical Medicine, Guangxi Medical University, 22 Shuangyong Road, Nanning, Guangxi 530021, People's Republic of China. ${ }^{4}$ Department of Cardiology, Institute of Cardiovascular Diseases, the First Affiliated Hospital, Guangxi Medical University, 22 Shuangyong Road, Nanning, Guangxi 530021, People's Republic of China.

\section{Received: 6 October 2014 Accepted: 23 February 2015} Published online: 07 March 2015

\section{References}

1. Skogsberg J, Kannisto K, Roshani L, Gagne E, Hamsten A, Larsson C, et al. Characterization of the human peroxisome proliferator activated receptor delta gene and its expression. Int J Mol Med. 2000;6:73-81.

2. Lefebvre P, Chinetti G, Fruchart JC, Staels B. Sorting out the roles of PPARa in energy metabolism and vascular homeostasis. J Clin Invest. 2006;116:571-80.

3. Semple RK, Chatterjee VK, O'Rahilly S. PPARy and human metabolic disease. J Clin Invest. 2006;116:581-9.

4. Lee CH, Kang K, Mehl IR, Nofsinger R, Alaynick WA, Chong LW, et al. Peroxisome proliferatoractivated receptor delta promotes very low-density lipoproteinderived fatty acid catabolism in the macrophage. Proc Natl Acad Sci U S A. 2006;103:2434-9.

5. Aberle J, Hopfer I, Beil FU, Seedorf U. Association of the $T+294 \mathrm{C}$ polymorphism in PPAR $\delta$ with low HDL cholesterol and coronary heart disease risk in women. Int J Med Sci. 2006;3:108-11.

6. Helisalmi S, Vepsäläinen S, Hiltunen M, Koivisto AM, Salminen A, Laakso M, et al. Genetic study between SIRT1, PPARD, PGC-1a genes and Alzheimer's disease. J Neurol. 2008;255:668-73.

7. Grarup N, Albrechtsen A, Ek J, Borch-Johnsen K, Jørgensen T, Schmitz O, et al. Variation in the peroxisome proliferator-activated receptor delta gene in relation to common metabolic traits in 7,495 middle-aged white people. Diabetologia. 2007;50:1201-8.

8. Yoshikawa T, Brkanac Z, Dupont BR, Xing GQ, Leach RJ, Detera-Wadleigh SD. Assignment of the human nuclear hormone receptor, NUC1 (PPARD), to chromosome 6p21.1-p21.2. Genomics. 1996;35:637-8.

9. Shin HD, Park BL, Kim LH, Jung HS, Cho YM, Moon MK, et al. Genetic polymorphisms in peroxisome proliferator-activated receptor $\delta$ associated with obesity. Diabetes. 2004;53:847-51.

10. Nilsson E, Poulsen P, Sjögren M, Ling C, Ridderstråle M, Groop L, et al. Regulation of skeletal muscle PPARS mRNA expression in twins. J Physiol. 2007;584(Pt 3):1011-7.

11. Robitaille J, Gaudet D, Pérusse L, Vohl MC. Features of the metabolic syndrome are modulated by an interaction between the peroxisome proliferatoractivated receptor-delta $-87 \mathrm{~T}>\mathrm{C}$ polymorphism and dietary fat in French-Canadians. Int J Obes (Lond). 2007;31:411-7.

12. Burch LR, Donnelly LA, Doney AS, Brady J, Tommasi AM, Whitley AL, et al. Peroxisome proliferator-activated receptor- $\delta$ genotype influences metabolic phenotype and may influence lipid response to statin therapy in humans: a genetics of diabetes audit and research tayside study. J Clin Endocrinol Metab. 2010;95:1830-7.

13. Nikitin AG, Chistiakov DA, Minushkina LO, Zateyshchikov DA, Nosikov W. Association of the CYBA, PPARGC1A, PPARG3, and PPARD gene variants with coronary artery disease and metabolic risk factors of coronary atherosclerosis in a Russian population. Heart Vessels. 2010;25:229-36.

14. Kim MY, Kang ES, Ham SA, Hwang JS, Yoo TS, Lee H, et al. The PPARS-mediated inhibition of angiotensin II-induced premature senescence in human endothelial cells is SIRT1-dependent. Biochem Pharmacol. 2012;84:1627-34.

15. Skogsberg J, Kannisto K, Cassel TN, Hamsten A, Eriksson P, Ehrenborg E. Evidence that peroxisome proliferator-activated receptor delta influences cholesterol metabolism in men. Arterioscler Thromb Vasc Biol. 2003;23:637-43.

16. Skogsberg J, McMahon AD, Karpe F, Hamsten A, Packard CJ, Ehrenborg E, et al. Peroxisome proliferator activated receptor delta genotype in relation to cardiovascular risk factors and risk of coronary heart disease in hypercholesterolaemic men. J Intern Med. 2003;254:597-604.

17. Miao L, Yin RX, Wu DF, Cao XL, Li Q, Hu XJ, et al. Peroxisome proliferator-activated receptor delta $+294 \mathrm{~T}>\mathrm{C}$ polymorphism and serum lipid levels in the Guangxi Bai Ku Yao and Han populations. Lipids Health Dis. 2010;9:145.

18. Jguirim-Souissi I, Jelassi A, Hrira Y, Najah M, Slimani A, Addad F, et al. +294T/C polymorphism in the PPAR-delta gene is associated with risk of coronary artery disease in normolipidemic Tunisians. Genet Mol Res. 2010;9:1326-33.

19. Gouni-Berthold I, Giannakidou E, Faust M, Berthold HK, Krone W. The peroxisome proliferator-activated receptor delta +294 T/C polymorphism in relation to lipoprotein metabolism in patients with diabetes mellitus type 2 and in non-diabetic controls. Atherosclerosis. 2005;183:336-41.

20. Pan SL, Luo XQ, Lu ZP, Lu SH, Luo H, Liu CW, et al. Microsomal triglyceride transfer protein gene $-493 \mathrm{G} / \mathrm{T}$ polymorphism and its association with serum lipid levels in Bama Zhuang long-living families in China. Lipids Health Dis. 2012;11:177.

21. Cooperative Meta-analysis Group of China Obesity Task Force. Predictive values of body mass index and waist circumference to risk factors of related diseases in Chinese adult population. Chin J Epidemiol. 2002;23:5-10.

22. Ruixing $Y$, Yuming $C$, Shangling $P$, Fengbing $H$, Tangwei $L$, Dezhai $Y$, et al. Effects of demographic, dietary, and other lifestyle factors on the prevalence of hyperlipidemia in Guangxi Hei Yi Zhuang and Han populations. Eur J Cardiovasc Prev Rehabil. 2006;13:977-84.

23. Miller SA, Dykes DD, Polesky HF. A simple salting outprocedure for extracting DNA from human nucleated cells. Nucleic Acids Res. 1988;16:1215.

24. Wang LF, Tan M, Chang H, Yu H, Shen JJ. Relationship of peroxisome. proliferation-activated receptor-delta +294T/C gene polymorphism with coronary artery disease. Acta Univ Med Anhui. 2008;43:701-5.

25. Akhmetov II, Astranenkova IV, Rogozkin VA. Association of PPARD gene polymorphism with human physical performance. Mol Biol (Mosk). 2007:41:852-7.

26. Pan SL, Wang F, Lu ZP, Liu CW, Hu CY, Luo H, et al. Cholesteryl ester transfer protein TaqIB polymorphism and its association with serum lipid levels and longevity in Chinese Bama Zhuang population. Lipids Health Dis. 2012;11:26.

\section{Submit your next manuscript to BioMed Central and take full advantage of:}

- Convenient online submission

- Thorough peer review

- No space constraints or color figure charges

- Immediate publication on acceptance

- Inclusion in PubMed, CAS, Scopus and Google Scholar

- Research which is freely available for redistribution 